\title{
FINITE ELEMENT ANALYSIS OF CRANE HOOK AND OPTIMIZATION USING TAGUCHI APPROACH.
}

\author{
Omkar P. Bhatkar', Arun V. Javir², Shinde Ajay Ashok ${ }^{3}$, Sawant Subodh Sumant ${ }^{4}$, Ukarde Suraj Eknath ${ }^{5}$, \\ Kavathankar Kunal Shivram ${ }^{6}$ \\ ${ }^{* 1,2}$ Assistant Professors and ${ }^{3,4,5,6}$ Students \\ *1,2,3,4,5,6 Mechanical engineering, Rajendra Mane College of Engineering and Technology, Ambav, Devrukh, \\ Ratnagiri - 415612, Mumbai University \\ *1Email: om.bhatkar@gmail.com, ${ }^{4}$ subodh3101993@gmail.com ${ }^{2},{ }^{5}$ suraj.ukarde2783@gmail.com
}

\begin{abstract}
: -
A Crane hook is a device for grabbing and lifting loads of heavy duty by mean of a device such as crane hoist. A crane hook is usually equipped with a safety latch to prevent the disengagement of the lifting rope to which the load is being attach.

The CAD model of a lifting crane hook is initially prepared from the Analytical Design. In the present report crane hook of trapezoidal section is modeled using UG-NX 8.0, further, importing the CAD model into ANSYS 15.0 we estimate until 20 tones i.e., equivalent to $200000 \mathrm{~N}$ load to be gradually applied, eventually we observed the von-misses stress developed in the model by FEM method these results von-misses stresses are being compared with Taguchi L9 orthogonal array for specific results.

Thus, these results would lead us to determine various stresses and deflections in the designed CAD model. In order to reach the most optimum model from different materials of hook would be tested and the most efficient material would be selected.
\end{abstract}

Keywords: - Trapazoidal section, Taguchi Analysis, Von-misses stress, FEM(Finite Eiement Method)

\section{(ㅇ) $\$($ (1)}




\section{INTRODUCTION}

Crane hooks are one of the important components used in industries to carry heavy duty loads; basically, crane hooks are designed with pulley elongated by rope or a chain. It is basically a hoisting fixture designed to engage a ring or link of a lifting chain or the pin of a shackle or cable socket and must follow the health and safety guidelines. Thus, such a crucial component in an industry must be fabricated and designed in a way so as to deliver maximum performance without breakdown.

Development of a hook is a long process which requires number of tests to validate the design and manufacturing variables. Hence, we have used CAE (Computer Aided Engineering) to shorten this development thereby reducing the number tests. A systematic procedure is obtained where CAE and tests are used together. In fact, their use has enabled the engineers to reduce product development cost and time while improving the safety, comfort, and durability of the crane hook they produce. This report is carried out on hook of trapezoidal CSA (Cross Section Area). The objective of this work is to carry out computer aided design and analysis of hook.

In this paper mathematical calculations are done for trapezoidal cross section with constant area of cross sections for different materials of structural steel and alloy steels analysis would be evaluated. UG-NX 8.0 design is prepared, for trapezoidal cross section by preparing the trajectory with the parameters taken from the design data book. However, result of mathematical calculations would be compared with the ANSYS with constant area of cross section, modifying the type of material optimization of better results were done in Taguchi Method (L9 orthogonal array). Thus, the aim of the work is to study the stress distribution pattern of a crane hook using FEM and to verify the results using Taguchi method.

\section{Suggested Strategies}

A crane is subjected to continuous loading and unloading. This may cause fatigue failure of the crane hook but the load cycle frequency is very low. If a crack is developed in the crane hook, mainly at stress concentration areas, it can cause fracture of the hook and lead to serious accidents. In ductile fracture, the crack propagates continuously and is more easily detectable and hence preferred over brittle fracture. In brittle fracture, there is sudden propagation of the crack and the hook fails suddenly. This type of fracture is very dangerous as it is difficult to detect. Strain aging embrittlement due to continuous loading and unloading changes the microstructure. Bending stresses combined with tensile stresses, weakening of hook due to wear, plastic deformation due to overloading, and excessive thermal stresses are some of the other reasons for failure.

Hence continuous use of crane hooks may increase the magnitude of these stresses and ultimately result in failure of the hook. All the above-mentioned failures may be prevented if the stress concentration areas are well predicted and some design modification to reduce the stresses in these areas. Thus, to minimize the failure of crane hook, the stress induced in it must be studied. The aim of this work is to explore the regions of high stress concentrations in the Hook which is an important engineering component.

\section{Material selection for the design procedure of crane hook \\ 3.1 Selection of Material:}

Many industries manufacture Hook by steel and alloy steel materials. These materials are widely used for production of hook and beams of different cross sections. Other than the load carrying capacity of hook, it must also be able to absorb the vertical load and deflection (induced due to variable loads). Ability to store and absorb more amount of strain energy ensures the safety of crane. The mechanical properties of materials are shown in the table below:

\begin{tabular}{|c|c|c|c|c|c|}
\hline \multirow[b]{2}{*}{ Sr. No. } & \multicolumn{5}{|c|}{$\begin{array}{l}\text { Parameters for Trapezoidal cross section and a load of } 20 \\
\text { ton on each. }\end{array}$} \\
\hline & $\begin{array}{l}\text { Material } \\
\text { selected }\end{array}$ & $\begin{array}{l}\text { Young's } \\
\text { Modulus } \\
\text { (E) } \\
\end{array}$ & $\begin{array}{c}\text { Poisson's } \\
\text { Ratio }\end{array}$ & $\begin{array}{c}\text { Tensile } \\
\text { Strength } \\
\left(\mathrm{N} / \mathrm{mm}^{2}\right) \\
\end{array}$ & $\begin{array}{l}\text { Density } \\
\left(\mathrm{kg} / \mathrm{mm}^{3}\right) \\
\end{array}$ \\
\hline 1 & $\begin{array}{l}\text { Structural } \\
\text { steel }\end{array}$ & $2.0 * 10^{5}$ & 0.3 & $800-950$ & 7850 \\
\hline 2 & AISI 4340 & $2.10^{*} 10^{5}$ & 0.29 & $700-850$ & 7850 \\
\hline 3 & AISI 4140 & $2.10 * 10^{5}$ & 0.3 & $300-380$ & 7899 \\
\hline
\end{tabular}

Table no.1

\subsection{Various types of load carrying hook:}

\begin{tabular}{|c|c|}
\hline TYPES & USED FOR \\
\hline One piece forged & Upto 100 tonnes \\
\hline Single Hook & Upto 50 tonnes \\
\hline Ramshorn Hook & Over 25 tonnes \\
\hline Laminated hook & Over 100 tonnes \\
\hline
\end{tabular}

Table no.2 


\subsection{Material and cross-section :}

Almost all type of crane hook are made up of steel 20 and trapezoidal section generally. Considered load acting on the crane hook is upto $200 \mathrm{kN}$.

\subsection{Selection of duty factor with the help of class}

Class of crane hook is selected by considering life of hook. We have select class 4 for better life of hook because it works for a longer time period continuously. However, the design calculated load comes to nearby 32 tonnes i.e equivalent to $320 \mathrm{kN}$.

\begin{tabular}{|c|c|c|c|c|c|}
\hline \multirow{2}{*}{ Class } & \multicolumn{2}{|c|}{ Duty factor } & \multirow{2}{*}{$\begin{array}{c}\text { Runs } \\
\text { hours/day }\end{array}$} & \multirow{2}{*}{\begin{tabular}{|c|} 
Total life \\
in hours \\
\end{tabular}} & \multirow{2}{*}{$\begin{array}{l}\text { Day/year of } \\
20 \text { Years life }\end{array}$} \\
\hline & Strength & Wear & & & \\
\hline 1 & 1 & 0.4 & 0.5 & Over 2500 & 250 \\
\hline 2 & 1.2 & 0.5 & 1.5 & Over 9000 & 300 \\
\hline 3 & 1.4 & 0.6 & 3 & Over 26000 & 333 \\
\hline 4 & 1.6 & 0.7 & Over 6 & $\begin{array}{c}\text { Over } \\
40000\end{array}$ & 333 \\
\hline
\end{tabular}

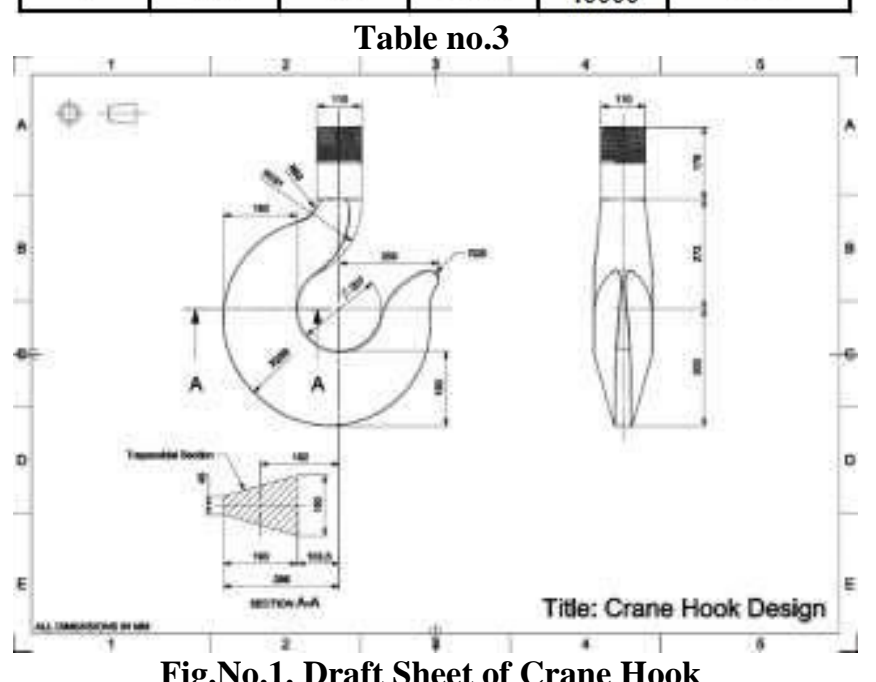

Fig.No.1. Draft Sheet of Crane Hook

\section{Experimental results}

CAD Modelling is the base of any project. Finite Element software will consider shapes, whatever is made in CAD model. The model of the trapezoidal cross section of hook is prepared by using UG-NX 8.0 software3D model of the Hook is shown in the fig. 2

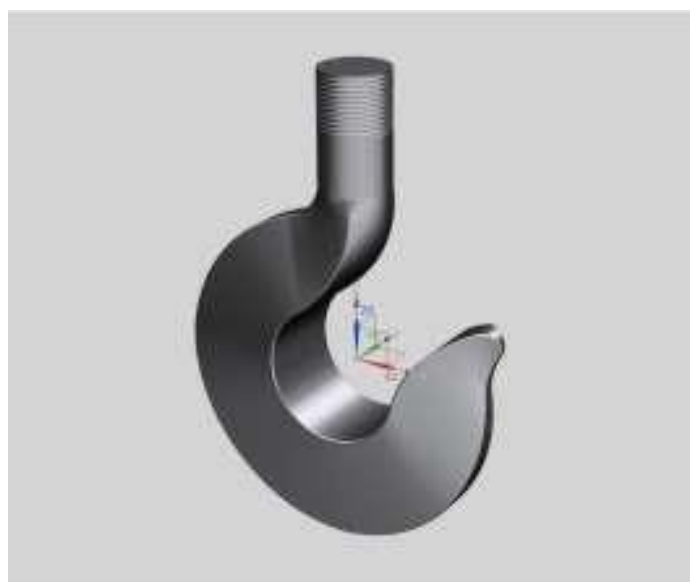

Fig.No.2. CAD model of crane hook

\section{Analysis of crane hook:}

Further cad model of the crane hook is imported to the ANSYS 15.0 using. step extension, then we generate meshing on the cad model.

Meshed model of crane hook is as shown in fig. 3 


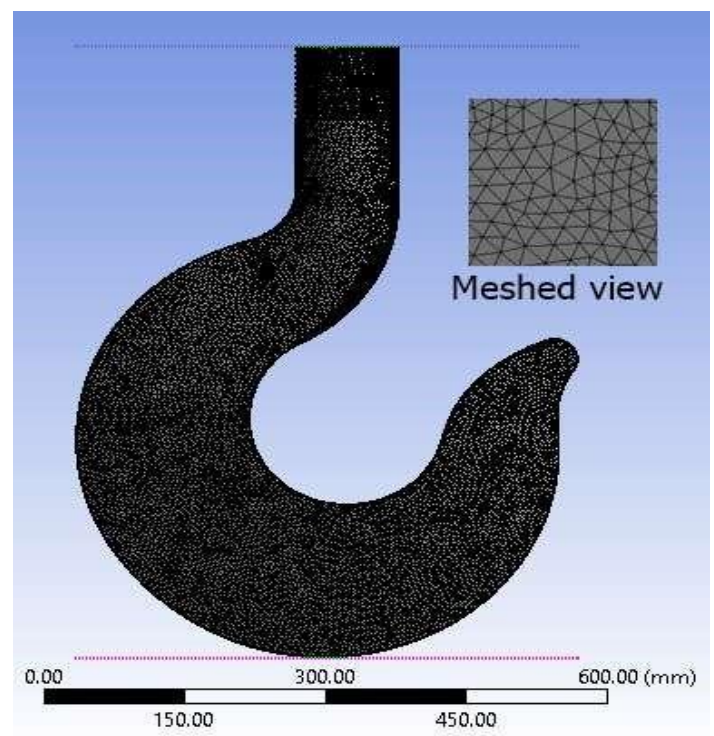

Fig.No.3. Meshed model of crane hook

Meshing Details :- No of Elements : :398388

No of nodes : :883955

Mesh method :Trapezoidal

Mesh size $\quad: 5 \mathrm{~mm}$

\section{Inflation :-}

Faces $\quad: 108$

Transition : smooth

Maximum Layer :5

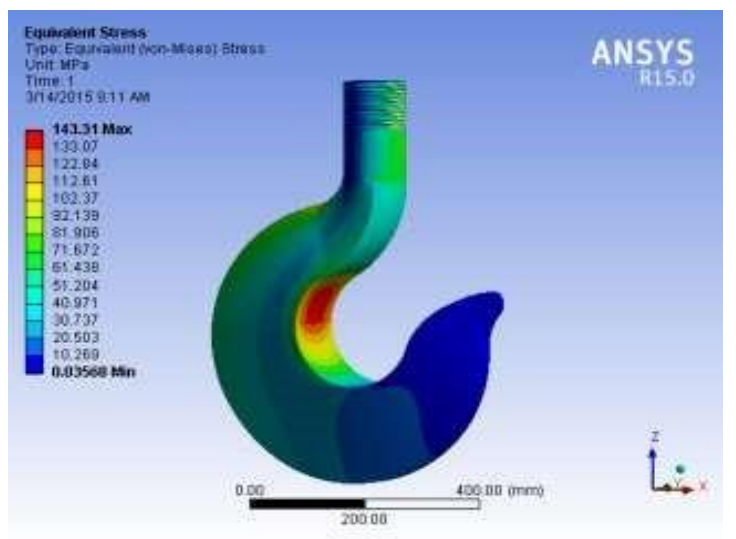

Fig.No.4. Stress analysis

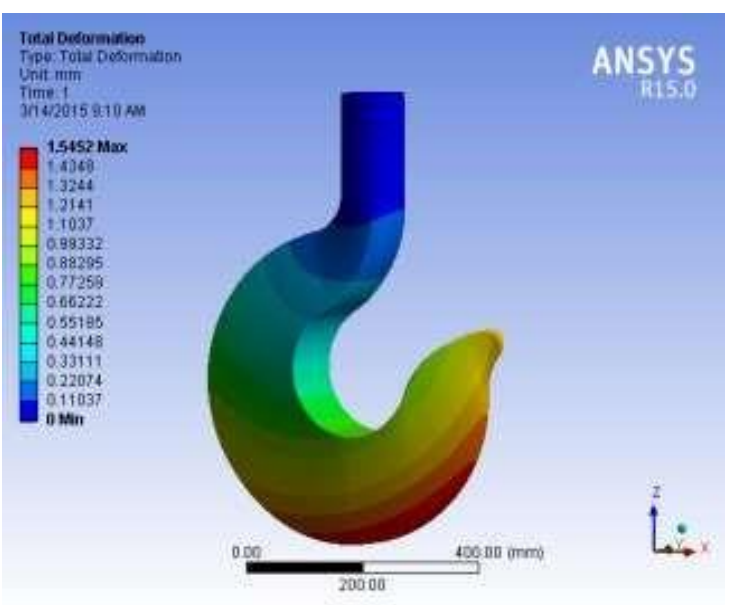

Fig.No.5. Deformation analysis 


\section{Taguchi Analysis:}

From above it is seen that large number of Equivalent stresses are developed in the model for 9 different combinations. Considering the minimum effective stress and deformation, we will go with "Smaller the Better" results of Taguchi method.

Taguchi method stresses the importance of studying the response variation using the signal to noise $(\mathrm{S} / \mathrm{N})$ ratio, resulting in minimization of quality characteristic variation due to uncontrollable parameter. The Equivalent Stresses was considered as the quality characteristic with the concept of "the Smaller-the-better". The S/N ratio for the smallerthebetter is:

$$
s / n=-10 \log _{10}\left(\frac{1}{n} \sum y^{2}\right)
$$

Where $\mathrm{n}$ is the number of measurements in a trial/row and $y_{i}$ is the measured value in a run/row. The $\mathrm{S} / \mathrm{N}$ ratio values are calculated by taking into consideration above equation with the help of software Minitab 17.

Taguchi approach was used for this design. The experiments were done with varying Load and Materials.

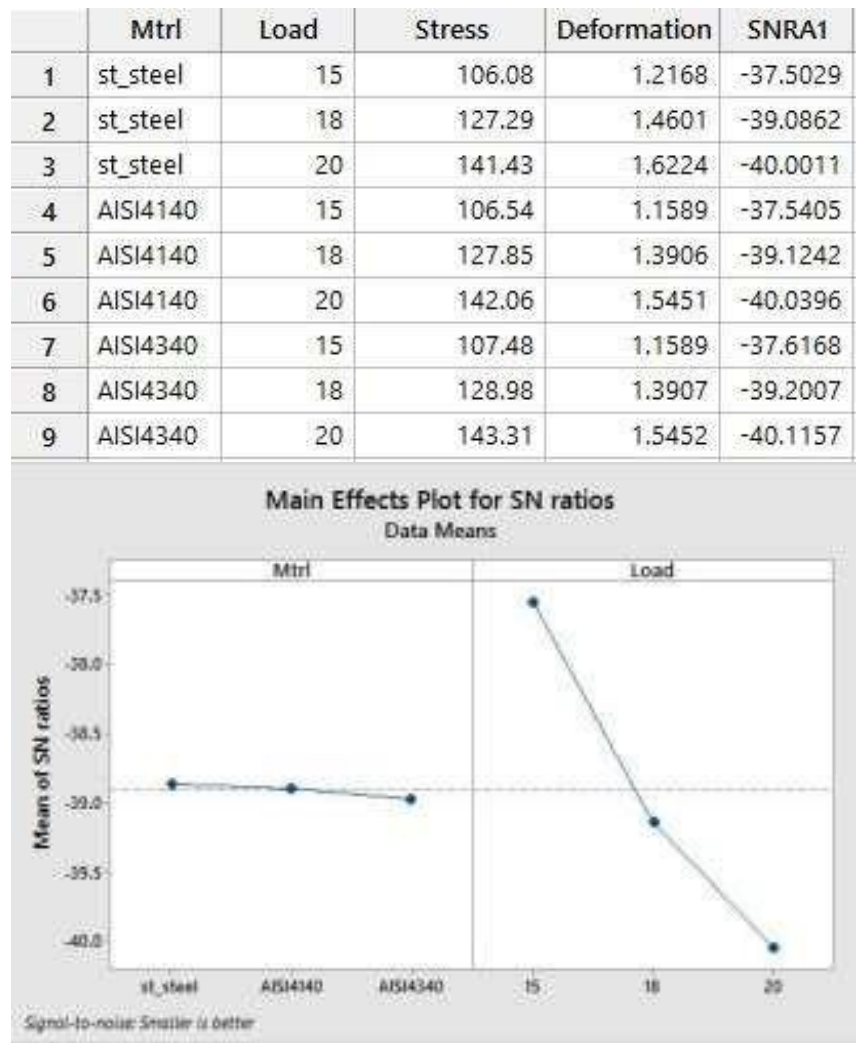

Fig.No.6. Taguchi result

\section{Feasibility in application}

This analysis will be useful to find out optimum material to be used in manufacturing of the crane hook in order to minimize the failure in the crane hook because of the various the stress induced within it as it is being subjected to varying load during its working life span.

By this proposed work eventually the life and the strength of the crane hook will be increased and a clear idea of variation in stresses between Analytical and Numerical results can be established.

\section{Conclusion}

Simulation and Analysis for the 3D model of a crane hook was being prominently done with the help of ANSYS software. Statics structural analysis was performed under the ANSYS. From static structural results, it is found that total maximum stress (i.e. von-misses) occurs at section AA as shown in figure no.1.Also the maximum deformation is induced on the tip of outer periphery, so we conclude that out of the 3 selected materials, AISI-4340 for 20 ton load is best suitable material for the manufacturing of the crane hook by considering the Taguchi results. Thus, we can state that maximum stress induced is $143.31 \mathrm{MPa}$ and the deformation induced is $1.5452 \mathrm{~mm}$ for material AISI 4340 which is having percentage error of 5.21 comparing with the analytical results.

\section{References}

[1] Santosh Sahu, Ritesh Dewangan, Manas Patnaik, Narendra Yadav, "Study of Crane Hook Having Trapezoidal Section by Finite Element Method \& Design of Experiments." International Journal of Modern Engineering Research (IJMER) www.ijmer.com Vol.2, 2779-2781, Issue.4, July Aug 2012. 
[2] Govind Narayan Sahu, NarendraYadav, "Design and Stress Analysis of various cross section of Hook." International Journal of Modern Engineering Research (IJMER) Vol. 3, 2249-6645 Issue. 4, Jul - Aug. 2013.

[3] Mr. A. Gopichand, Ms. R. V. S. Lakshmi, Mr. B. Maheshkrishna, "Optimization Of Design Parameters For Crane Hook Using Taguchi Method”, International Journal of Innovative Research in Science, Engineering and Technology (An ISO 3297: 2007 Certified Organization)Vol. 2, 2319-8753, Issue 12, December 2013.

[4] Mr. A. Gopichand, Ms. R.V.S.Lakshmi, Mr. B. Maheshkrishna, “Optimization Of Design Parameters For Crane Hook Using Taguchi Method", International Journal of Innovative Research in Science, Engineering and Technology (An ISO 3297: 2007 Certified Organization)Vol. 2, ISSN: 2319-8753, Issue 12, December 2013.

[5] Ajeet Bergaley, Anshuman Purohit "Structural Analysis of Crane Hook Using Finite Element Method", International Journal of Science and Modern Engineering (IJISME) ISSN: 2319-6386, Volume-1, Issue-10, September 2013.

[6] Patel Paresh and NiravKamdar, "Design and Analysis of Major Component of 120 Tones Capacity of EOT Crane" 2014 IJEDR, Volume 2, Issue 2, ISSN: 2321-9939; 2014.

[7] T. Muromaki, K. Hanahara, Y. Tada, S. Kuroda and T. Fukui "Estimating load condition having caused structure failure and an optimal design taking account of the estimated result" 5th International Conference on Reliable Engineering, 387-406, 2012.

[8] Narvydas E., Puodziuniene N., Circumferential stress concentration factors at the asymmetric shallow notches of the lifting hooks of trapezoidal cross-section. Mechanika, Volume 18(2): 152-157, 2012. .

[9] S. Vinodh, R. Ravikumar,,"Application of probabilistic finite element analysis for crane hook design", Journal of Engineering, Design and Technology, Vol. 10, 255 - 275, 2012 [10] M. Shaban, M. I. Mohamed, A. E. Abuelezz, T. Khalifa, "Determination of Stress Distribution in Crane Hook by Caustic", International Journal of Innovative Research in Science, Engineering and Technology ISSN: 2319-8753 Vol. 2, 1834-1840 Issue 5, May 2013.

[11] M S. Phadke 'Quality engineering using robust design', Pearson Education India Limited, Edition 2006.

[12] R. Uddanwadiker, "Stress Analysis of Crane Hook and Validation by Photo Elasticity," Engineering, Vol. 3 No. 9 , 935-941, 2011. 